\title{
The Current Organization and Administration Situation of the Secondary Education Units in the North Aegean Region
}

\author{
Dimitrios Ntalossis, George F. Zarotis* \\ University of the Aegean, Faculty of Human Sciences, Rhodes, Greece \\ *Corresponding Author \\ Dr. George F. Zarotis
}

\section{Article History}

Received: 14.12 .2019

Accepted: 24.12 .2019

Published: 30.12 .2019

\begin{abstract}
After analyzing various studies, we can conclude that the elements characterizing an effective school unit are leadership, teachers, and communication among school unit members, the climate of a school unit, school culture, the logistical infrastructure, the school's relationship with the local community, and the administrative system of the educational institution. The ultimate goal of this research is to detect the current organization and administration situation of secondary education units. In particular, to examine the concept of education, the school role and the concept of effective school, to identify the existing model of administration of the educational system, the organization and administration models of the school unit in which the respondents work, and furthermore the school culture level. The method adopted for the study is the classified cluster sampling method. According to this method, clusters are initially defined, which in this case are Secondary School Units. The clusters are then classified according to their characteristics, which in this case was the geographical feature: they all belonged to the North Aegean Region. In this context, 312 questionnaires were sent to all 104 secondary schools of the North Aegean (Lesvos, Chios, Samos, Ikaria, Limnos, Fourni, Oinousses, Psara, Agios Efstratios). Out of the 312, 148 were returned completed. This means a $47.44 \%$ response rate. According to the survey results, the overwhelming majority of secondary schools in the North Aegean Region does not have a secretary at the school, and the principal already has several responsibilities, while the big problem is the centralized and bureaucratic nature of the administrative organization model of the educational system, but also of the administration and organization of the school units. The nature of this model makes it incomplete, time-consuming, perfunctory, irrational, inadequate and ineffective, which means that principals and teachers do not have the flexibility to take initiatives that will improve the quality of education and teaching at the school unit they serve according to the needs of students and the local community, and based on the school's connection to the wider society and the changes that are taking place in its environment. Moreover, it was emphasized that this model, in addition to making school units more difficult to operate, also results in a misallocation of staff and consequently increased costs.
\end{abstract}

Keywords: Organization and Administration, School Unit, Secondary Education.

\section{INTRODUCTION}

This research makes a reference to the main models of the organizational theory and functioning of school units. An important reason why it is useful to analyze the organizational and operational theory of school institutions is that the effectiveness of a school unit depends on the organizational theory adopted. In order for educational organizations, or otherwise educational units, to accomplish their purpose, effective management is a prerequisite. After all, several studies have shown that both student progress and behaviour depend on the characteristics and management of the educational unit. Leadership plays an important role in the management of school units, while at the same time it is a significant factor in connecting the school with the local community and in achieving school effectiveness. As regards the factors that contribute to school effectiveness, the above analysis has shown that there is an inseparable link between school unit leadership and school effectiveness. It should not be considered that leadership has only a direct impact on learning outcomes but also an indirect on the school unit through its influence on school organization and school culture [1]. An effective school principal-leader assists and supports teachers, while overseeing the educational work, and also encourages and promotes the involvement of teachers and parents in the decision-making process, which leads to the commitment of teachers to the school organization and increases their job satisfaction and performance [2].

Copyright @ 2019: This is an open-access article distributed under the terms of the Creative Commons Attribution license which permits unrestricted use, distribution, and reproduction in any medium for non commercial use (NonCommercial, or CC-BY-NC) provided the original author and source are credited. 
School principals are considered to be the most critical factor contributing to the reorganization of the school [3], based on changes in the external environment of the school unit, as well as the demands of parents, pupils and the local community. Indeed, Rhodes and Brundrett [4] report that school improvement has been linked to activities that aim to change school and the educational system, and which enhance school effectiveness by increasing the desired outcomes for learners.

According to surveys, school principals are responsible for four main areas. The first is to evaluate the effectiveness of teachers, the second is to provide a supportive climate, the third is to convey the mission and purpose of the school to those involved in the educational process, and the fourth is to provide a climate that encourages learning. In addition, school principal's responsibilities include team orientation and encouraging professional development [5].

In addition to the principal, school culture is an important factor contributing to the effectiveness of the school unit. The conditions of the educational unit's operation and the goals it sets over time determine the success and appropriateness of its culture. We could say, however, that successful culture is reflected in its human potential, and it can be seen when one is willingly working and participating in it. Another factor is the school management model. The decentralized management model has the advantage of leading to speed and flexibility in the decision-making process $[6,7]$.

\section{Methodology}

According to the relevant literature [8], the two methodologies available are qualitative and quantitative. Quantitative research is largely structured and produces objective data that can be quantified and statistically processed, whereas qualitative research is interpretive and produces descriptive data, taking into account the diversity of subjects and arguing that reality is not objective, but is shaped by the opinions, attitudes and behaviours of individuals [9]. For the purpose of the present work, quantitative research was selected. According to Creswell [10] the two main methodological tools used in quantitative research are experiments and surveys using questionnaires or structured interviews. For the purpose of this study, the questionnaire was used as the most appropriate methodological tool. The questionnaire is a practical data collection tool that provides numerical data, can be delivered without the presence of the researcher, while it is easy to understand and easy to analyze [11], as its data can be easily coded and produce results [12]. Also, the anonymity provided while completing the questionnaire, as well as the high degree of validity and reliability, probably encouraged the respondents to participate, something that, we presume, provided a larger sample for our survey. This was another factor that we also took into consideration for choosing the questionnaire as a research tool [13].

The questionnaire consists of two sections and a total of 19 questions. The first section consists of questions 1-11 and refers to the demographics of the respondents: gender, age, school district, years of service as a teacher at the specific school, specialty, marital status, studies, writing activity and training seminars attendance or management post-training studies. The second section consists of the questions 12-19 and aims to detect the current situation. More specifically, this section examines the concept of education, the role of the school and the concept of an effective school, the definition of the existing model of administration of the educational system, the models of organization and administration of the school in which the respondents serve, as well as the degree of school culture.

The method adopted for the study is the classified cluster sampling method. According to this method, clusters are initially defined, which in this case are Secondary School Units. The clusters are then classified according to their characteristics, which in this case was the geographical feature: they all belonged to the North Aegean Region. In this context, 312 questionnaires were sent to all 104 secondary schools of the North Aegean (Lesvos, Chios, Samos, Ikaria, Limnos, Fourni, Oinousses, Psara, and Agios Efstratios). Out of the 312,148 were returned completed. This means a $47.44 \%$ response rate.

\section{Results of the Statistical Analysis Demographic data \\ Gender}

86 men $(58.1 \%)$ and 62 women $(41.9 \%)$ took part in the study.

\section{Age}

As can be seen from the graph below, the majority of respondents (28.4\%) are 46-50 years old. Following are those aged $36-40$ years $(20.3 \%), 31-35$ years (15.5\%), $51-55$ years $(14.2 \%)$ and $41-45$ years $(13.5 \%) .4 .1 \%$ are $25-30$ years old, $2.7 \%$ are $56-60$ years old, and there is a $0.7 \%$ (one person) aged over 60 .

\section{Region to which the school where the respondents work belongs}

In terms of the region to which the school where the respondents work belongs, the majority (49.3\%) work at schools in Lesvos, $15.5 \%$ in Chios, $10.1 \%$ in Lemnos, $9.5 \%$ \% in Samos, $6.8 \%$ in Ikaria, $4.1 \%$ in Psara, $2.7 \%$ in Agios Efstratios and lastly $2 \%$ in Fourni. 


\section{Years of service as a teacher}

The majority of the respondents $(26.4 \%)$ have been working as teachers for $6-10$ years. $25 \%$ have a teaching work experience of $11-15$ years, $22.3 \%$ have been working as teachers for five years, $14.2 \%$ over 20 years and $12.2 \%$ for $16-20$ years.

\section{Years of service in the particular school}

The majority of the teachers who participated in the survey (68.9\%) served in the particular school unit for up to five years. $16.9 \%$ have been working in the same school for $6-10$ years, $10.1 \%$ for $11-15$ years, $3.4 \%$ over 20 years and $0.7 \%$ between $16-20$ years.

\section{Specialities}

As can be seen from the graph below, the majority of teachers $(23.6 \%)$ are physical education teachers (PE* 11$)$, while $23 \%$ are language teachers (PE 02). 10.1\% are mathematics teachers (PE 03), while the same percentage stated that they are physics/chemistry/biology teachers (PE 04). 8.8\% are theology teachers (PE 01), 6.1\% are English teachers (PE 06), 5.4\% are German teachers (PE 07), 3.4\% are French teachers (PE 05), 4.1\% are IT teachers (IP 19), while 2\% are art teachers (PE 08) and teachers of economics (PE 09). Finally, one person (0.7\%) is a chemical-mineralogist (PE 12) and also one person is a teacher of accounting (PE 18).

${ }^{*} P E=$ Speciality Code

\section{Marital Status}

With regard to the teachers' marital status, $45.9 \%$ are married with children, $27.7 \%$ are single, $14.9 \%$ are married without children, $10.1 \%$ are divorced, and there is one person $(0,7 \%)$ who is widowed.

\section{Attending administration training seminars}

The majority of teachers (58.8\%) stated that they have attended management seminars. $3.4 \%$ (5 people) did not answer this question.

\section{Further training in administration}

Out of the $75.7 \%$ of the respondents who answered this question, $53.4 \%$ (70.5\% of all teachers) stated that they have not been trained in administration, as opposed to $22.3 \%$ of the teachers. ( $29.5 \%$ of the teachers in total).

\section{Writing activity}

$73 \%$ of teachers reported that they did not develop writing activity as opposed to $25 \%$ of the respondents. Also, it is noteworthy that $2 \%$ (three people) did not answer this question.

\section{Other, beyond basic, studies}

Out of the $62.2 \%$ of the teachers who answered this question, $32.4 \%(52.2 \%$ of all teachers) stated that they had a postgraduate degree, $4.7 \%$ (7.6\% of teachers in total) has another university degree, only $4.1 \%$ (6.5\% of all teachers) has a doctorate degree, while $20.9 \%$ have had other studies ( $33.7 \%$ of teachers in total).

\section{Current situation \\ School secretary}

The overwhelming majority of teachers (95.9\%) responded that the school they serve does not have a secretary. $2 \%$ (three people) did not answer this question. Regarding the responsibilities of the school principal, $59.5 \%$ of the teachers believe that they are sufficient, while $37.2 \%$ believe that they should be expanded.

\section{Concept of education and school purpose}

According to a teacher's answer, the student should be at the centre of the education. It was also mentioned that by utilizing experiences, knowledge and creative ideas, education can be upgraded. The concept of education is to provide students with the necessary equipment for their lives, as well as to teach them to behave, to acquire critical thinking, to love knowledge, to acquire professional skills, to form characters and behaviours. As another teacher mentioned, "education means nurturing children from childhood, edifying and educating them". Education was described as 'systematic learning process'. Education should contribute to the development of intelligence, character formation, transmission of national culture, to provide pupils with skills and competences. Education should "form active citizens that have the desire and ability to participate in activities such as environmental protection, health promotion, and cultural heritage". "The concept of education is the organized learning process that takes place within the school. The goal of education is to make children love learning and furthermore help them acquire critical thinking rather than parrot. To respect diversity and create conscientious citizens." As one teacher puts it, "the main purpose of school is to educate children and adolescents in order to complete their spiritual, social and moral development, and that is the concept of education". According to another view, education is "the way a civilization perceives the value of a person's intellectual, moral, musical and physical abilities and their cultivation from an early age through school". Education is considered by a teacher to be "action directed by the adult 
generations to generations not mature yet for social life." Finally, it is worth noting that one teacher responded to this question saying that the concept of education and the purpose of school are understood 'as defined in Article 1 of the PD. 82 ». In the same context, another participant's response was: "According to the Constitution, education is a fundamental mission of the State and is aimed at the moral, spiritual, professional and physical education of Greeks, the development of national and religious consciousness and their formation to free and responsible citizens."

More specifically, the purpose of the school, according to a teacher's response, is to create a "society of excellent people" and not just a "society of likable people". Another teacher mentioned that the pedagogical task is difficult, and that the purpose of school is to give children love, maximize their self-knowledge and self-esteem. According to another view, the school, as an institution of socialization, should help students form their character, cultivate their minds and convey culture. One of the teachers stated that "the school should be attractive to students, keep pace with social reality, cultivate personality and provide students with comprehensive, integrated education", while according to another view, the purpose of school is "the systematic and organized process of education and learning". An interesting point was cited by yet another teacher who stated that "the purpose of school is to love children, to listen to their pain and joy, and to cultivate them intellectually."

As mentioned by another participant, "the purpose of school is the holistic and balanced development of students' mental, intellectual and physical personality, and to integrate them harmoniously into society. Achieving the school purpose or objectives essentially reflects the concept of education." This view is also shared by another teacher, who added that within the school's objectives is that the students receive influences from society and learn the concept of solidarity. Another view is the following: "the formation of citizens good and virtuous according to the standards of our ancient ancestors, capable of meeting the modern needs of society and smoothly coexisting with the rest of society's members".

Another teacher spoke of the school role as a carrier of tradition, especially in today's era, saying that "school is the most important means of transferring the wealth of tradition from one generation to the next, because with the new development of economic life, the family role as a carrier of tradition and education has weakened." In a similar vein was the response of another teacher, who stated that "the purpose of the school is to teach the Greek language and the Orthodox religion, to preserve the Greek identity and to prepare students to participate in society activities."

According to another answer, the school ought to "develop integrated, mentally cultured, personalities. Children should be happy at school and not gloomy and troubled." In fact, "under the current situation, school outweighs even family. School should not fall short of love. After all, it is a society with its laws, regulations and disciplined freedom, and there is respect for the rights of others. The child matures, becomes more serious, disciplined, and develops self-control". The purpose of school is "to contribute to the comprehensive, harmonious and balanced development of the students' mental and psychosomatic powers so that they can develop into integrated personalities and live creatively". The school "needs to open a window of communication with society, prepare citizens that have views and judgment. The school should oftentimes leave the textbook in order to follow or adapt to developments," according to a teacher's reply. Another point, which focuses on a number of different parameters, is the following: 'the new school emphasizes synergy and coordination. It reinforces the role of teachers in the process of upgrading school with self-motivated initiatives and innovation incentives, taking into consideration the knowledge that is required to fulfil their high mission and with a correspondingly high status, position in society and pay. "

Another yet teacher mentioned the positive role of today's school, and expressed the view that "in today's school students develop at the same time autonomous action, collective social spirit and environmental awareness (via the programs that are carried out)".

The purpose of school is the multifarious physical and mental development of students, i.e. to offer them guidance and a vision, to help them visualize a better tomorrow, to provide them with the knowledge they need to solve their day-to-day problems, and to act with success in every facet of their lives. Furthermore, the school should help students gain respect, think freely, learn to behave properly, to develop strong will and integrated personality, to acquire social and political consciousness. Apart from the above, the purpose of school is to develop moral awareness, to morally uplift the individual.

According to another teacher: "The purpose of school is the overall education of students and the cultivation of their personality. The school must develop students' critical thinking and social reflection, participation and solidarity. Respect for diversity, connecting human beings with society and the environment, with the general aim of creating an integrated citizen who can participate in "social life". At school, knowledge must be acquired through reflection and understanding, the active involvement of students by the method of research, and the constant communication between students and teachers".

Finally, it is worth mentioning another respondent's very interesting point of view: "School is a social institution; it is the basic ideological mechanism of the state. Its basic function is the social reproduction of the unequal structure of society and the privileged classes from generation to generation. We now see this clearly with the state's minimum education funds. The state doesn't provide 
free transfer for students, they have to pay for books, or tuition at Universities. In a little while, education will be only for the rich". In this context, a teacher mentioned that "the school is preparing young people for the role they will have to take on in the system later".

Another teacher shares the same view: "school is the basic ideological mechanism of the state, serving the requirements of the mode of production (now with the new laws this is more evident). Inequality is reproduced."

The fact that the school is not fulfilling its purpose was pointed out by another teacher who stated that "students do not like school as it is today. Parents do not trust it (see private lessons) and teachers are not inspired by it. It is an outdated school, disconnected from modern reality, while it should have been attractive to both students and teachers."

The ugly situation of today's education system is clearly depicted in another teacher's response: "In education today we are overloaded with material, textbooks lead to frontal teaching, narration and memorization. Students are evaluated on their ability to learn by heart. Student-cantered teaching approaches that recognize the uniqueness of each student and of each classroom must be promoted."

As another teacher put it: "Cultivation of the mind today is as essential as food for the body. The purpose of school is to promote culture. School is the most important and effective means of understanding and transmitting our culture from one generation to another. Since modern civilization is undergoing a crisis of values, this crisis does also affect school. Today's school unfortunately provides simple knowledge, but not education."

\section{The concept of effective school}

According to a teacher, a school is defined as effective when there are basic teaching approaches, such as:

- A cross-thematic approach for the multifaceted supply of knowledge

- Work plans, so that memorization can give way to research

- Teaching in groups, in order to strengthen the collective spirit

- Diversified pedagogy, which addresses the needs of the student and not the classroom in general

- Exploiting new technologies in teaching, a key factor in the new reality, which is the digital school

According to the opinion of another teacher, in an effective school there should be:

- Parental involvement

- Order and discipline

- $\quad$ Adaptation to local conditions

- Cooperation, coordination and good relations between colleagues

The appropriate school principal with knowledge and skills, who will understand teachers that are not local, but also the collaboration between teachers is what characterizes an effective school,

According to a participant's answer: "A school is effective when it engages students' interest and answers all their questions. Students gladly attend it, and according to their skills, an effective school will guide them to find work or, at least, assist them to choose the right career path." Another teacher considers that "effective school has both the logistical infrastructure and well-qualified teaching staff to provide meaningful education that students will assimilate." Another view sets out several parameters: 'new pedagogical techniques, a more flexible learning environment, experiential learning, more active involvement of students in their personal learning activities and planning, utilizing new technologies and personalizing teaching to a greater extend". In this context, it was stated that "according to the definition of the new school, the effective school is: open, digital, innovative, all-day [...], using upgraded curricula and teaching methods". However, effective schooling is more than what has been mentioned by the respondents so far, as furthermore it is the school that places great emphasis on the connection with the local community and wider society. Another teacher considers that: "Effective school fosters in students environmental awareness; it is open to society and in harmony with the new administration architecture. The new school is linked to the local communities; it is the school where everyone has an institutional and essential role: teachers, parents, students, local government. The country's new administrative structure is the basis for a new relationship between education and local society, with new responsibilities being transferred under the Constitution." A school is considered to be effective "when it detects students' inclination, nurtures and provides them with opportunities for their professional development. It is also the school that produces informed citizens. "

The creation of a new curriculum was emphasized by one of the teachers, who argued that the school in order to be effective, taking into account the new goals set, should have to develop a new curriculum. It should be goal oriented, clearly describe the development of the basic knowledge and skills from which teaching and assessment methods will be derived. It should be open and flexible with respect to the teacher, who will be able to intervene and influence the content and method of teaching." An interesting definition was given by one teacher who stated that effective schooling is defined as "the ability of the institution to achieve measurable educational goals". Another view of an effective school is this: "the school that contributes to the autonomous building of personalities - active citizens, that transmits knowledge, encourages discourse among its members and with society in general, explores, tolerates, discusses, respects, promotes reflection, freedom and participation." 
One participant emphasized that a school is effective when "it functions well in its daily routine, confronts students' problems and is close to them without disrespecting their values and ideals".

Further points that have been mentioned regarding the concept of an effective school are the following:

- There should be quality in education

- All should have equal opportunities

- The school should understand and respect the particularities of each student

- $\quad$ There should be high success rate in student exams

- $\quad$ There should be a high degree of consistency between teachers as well as between principals and teachers

- The principal should communicate well with the teachers and there shouldn't be any problems in the interpersonal relationship between teachers, students and the principal

- There should be communication and cooperation with parents and the local community

- There should not be any problems with students' behaviour

- Teachers should be provided with incentives

- Goals set at the beginning of the school year should be achieved

- There should be expectations as regards students

- There should be a safe environment

- Teachers should be diligent

- There should be continuous effort to improve the school unit

- Lack of school violence

- There should be love for children, patience and perseverance from all participants

- School should develop students' collegiality and their critical thinking

- Teachers should receive lifelong learning and continuous training

- The building facilities should be effective and in good condition

- There should be no restriction on creativity and imagination

- $\quad$ The school should encourage creative attitude to life and inspire for something better

- It should contribute to the awakening of consciousness

- It should have stable staff

- Students should be involved in a range of school, as well as extra-curricular, activities such as theatrical and environmental activities

- The school should create ethical and intellectual people who are capable of offering primarily to other human beings and society.

- It should cultivate students' sensitivity and imagination, and create people with intellectual concerns and interests.

- Tasks should be adopted to the specific needs of student population and to local conditions.

Factors associated with an effective school

The graph below illustrates those factors associated with effective schooling. Teachers believe that the factors that are most strongly associated with effective schooling are:

- Implementation of incentives for teachers by the school principal (58.8\%)

- Support climate (55.4\%)

- Cooperation among school members (52.7\%)

- Continuous development and training of teachers (50\%)

- Effective leadership (49.3\%)

- High degree of coherence and spirit of cooperation between teachers (49.3\%)

- Interaction and communication between school unit members (48\%)

- Effective management of the school unit (45.3\%)

The factors associated with effective schooling to a large extent are:

- $\quad$ Frequent monitoring of student progress (55.4\%)

- Unambiguous and clearly defined objectives (53.4\%)

- $\quad$ The teaching method (53.4\%)

- Managing teaching and classroom organization strategies $(52 \%)$

- High level of staff involvement in the development of school objectives (51.4\%)

- The structure of the school organization $(51.4 \%)$

- Unambiguous and clear mission of the school (51.4\%)

- Learning opportunities and adequate time to carry out the learning process (51.4\%)

- Interaction and communication between school unit members and the local community $(50.7 \%)$

- System for controlling and monitoring the performance of the school unit (50.7\%)

- Increased quality of education (50\%) 
- Existence of a value system (49.3\%)

- Procedures to be followed (general school administration, personnel administration, etc.) (48.6\%)

- Equal access to education for all (48\%)

- High expectations of students (48\%)

- Involvement of teachers, students and the community in the fund allocation process (47.3\%)

- Collaboration between school members and the local community $(44.6 \%)$

- Recognition of the improvement process by the school leadership (42.6\%)

- High participation of staff, parents and all concerned in the decision-making process (42.6\%)

- Safe and healthy school environment (41.9\%)

- Active involvement of parents and their support in school efforts (39.9\%)

- School culture (36.5\%)

Finally, the implementation of inclusive policies is considered to be moderately effective (36.5\%).

\section{Current situation with regard to the model of administrative organization of the educational system}

According to the view of the majority of the teaching staff bureaucracy prevails; a situation that makes very difficult evens the simplest actions. Some teachers reported that while computers and access to the Internet are available, all procedures are handwritten, while according to another view, there were no pictures of students on their tabs, as is usual in other European countries and in this case England. Another teacher stated that school principals should be allowed to decide on certain issues on their own without necessarily the approval of the head office each time.

Some participants stated that the current situation is inadequate and ineffective, while another stated that it had no "permanent goals, there are constant and unnecessary changes that are deviating from the real purpose of the educational system". In this context, it is worth pointing out an interesting view of one of the participants, who described the current state of the administrative organization model as "modest, meaningless, nepotistic bureaucracy, as a result of the lack of purpose and meaning of our educational system". The rigorous and dry bureaucratic model "does not give school units the opportunity to act according to their pupil potential and their school identity that depends on local socioeconomic factors". According to another view, the current model of administrative organization is characterized as rough and "irrational, without a concrete and firm strategy, without long-term planning". Another point of view is: "Laws and rules exist. Those in the administration are trying to soften the rules, moderate the restrictions, not to apply those that affect interests, persons and situations."

Despite the negative responses, one teacher described the current situation as "quite good, but it also needs further improvement and effective use of whatever financial resources is at our disposal." In addition, despite the negative answers of the respondents' majority, another teacher stated that the administrative organization of the educational system "is trying to become a Total Quality Management involving all members of the school community". According to yet another view, "given the circumstances, the current situation of the administrative organization of the educational system is satisfactory, as it is decentralized. It can however be improved by more rational organization, such as the integration of Primary and Secondary Education Directorates." In the same context, one participant stated that "the organization model of the educational system does not need any change. What is needed is its implementation, and not let everyone do whatever they want." Another positive response from one of the participants is the following: "Although the bureaucratic system generally prevails, in many cases the decentralized administration system has begun to prevail, more authority is given to local institutions and school principals."

In their majority, teachers described the existing model of administrative organization as bureaucratic, problematic, centralized, inadequate, convoluted, time-consuming, outdated and incomplete, while one teacher characterized it as formalistic and vindictive. It was also mentioned that "the bureaucracy that exists is a factor of delays, and as a result the organization is cumbersome and there is an unequal and irrational distribution of staff at enormous cost". Consequently, most of the teachers reported that this model should be improved and / or changed, and that there is need to simplify procedures and the multitude of laws and regulations in force. It was also suggested by one teacher that several opportunities for important decisions should be given to the Region, while another respondent stated that the administrative organizational model should include the following elements: Planning, Organization, Management, Control and Coordination.

\section{Organizational model of the school unit}

The majority of teachers stated that the organizational model followed by their school unit is bureaucratic (58.8\%). The next model used by $14.9 \%$ of the school units involved in the survey is the human relations theory and the participatory management model $(13.5 \%)$. The least followed model is the decentralized administration system $(1.4 \%)$.

\section{Administrative model of the school unit}

The majority of the school units that participated in the survey followed the bureaucratic management model with $54.7 \%$. The next immediate model used is management focused on school objectives (16.2\%), followed by responsible management (13.5\%) and finally educational management (11.5\%). 


\section{Definition and character of the school culture in the school units where the respondents serve}

According to a teacher's response, there is a high degree of culture in the school unit he serves. In particular, "colleagues encourage the values of independence, respect, professionalism and the autonomy of each colleague in the classroom", while at the same time "they respect leadership and avoid conflicts".

According to another teacher who described the level of culture as high, there are codes of conduct, announcements, a school newspaper, student assemblies and staff meetings that reveal the true values of the school. Specifically, one teacher stated that "there is a high level of culture, there is a system of shared values, such as cooperation, trust, open communication, mutual respect. These values define the character and the identity of the school." In the same context, of the high level of school culture, according to another point of view: 'the deepest level of culture consists of collective assumptions related to human nature, human relations, the environment, e.g. that teachers form a family in which they accept and respect each other; they are responsible and able to make decisions for the good of their students."

Another teacher described school culture as good, since "students and teachers actively participate and help the group they belong to, they work with other members for common purposes, and most importantly they do not attack other members for their motives." However, one teacher stated that although there is a pleasant atmosphere among teachers, common goals, expectations and emphasis on teaching, there is no bonding among students as there are many students from other countries. One of the respondents spoke about the effort to create school culture, by the cooperation of teachers, parents, students and the local community in order to promote a collaborative and creative model of student socialization, "which inspires respect to the personality of students, teaching staff, or to anyone involved, in the spirit of a holistic administration." Another teacher said that classrooms and sports facilities are very poor, while human relations are excellent.

More than satisfactory described another teacher the behaviours, perceptions and opinions of teachers and students, while one respondent described school culture as satisfactory. According to another answer: "Due to the fact that the purpose of school is not served by the curricula, school culture is not shaped as an integration of personality, but as a stressful search for future professional rehabilitation in every way." According to other views, culture in school units can be described as satisfactory or even quite good, as "the climate is generally democratic and collective".

A teacher, however, reported that the level of the school culture is low in the unit he serves, while another respondent reported that "there is a negative tendency in behaviour". Also, one professor said he could not discern school culture noticeably, possibly because he did not have many years of service as a teacher. According to another teacher's opinion: "I see a picture somewhat repulsive and the climate is not that creative. It is probably because of the negative financial situation, no one wants to do something more without reward, and even more now that our salary has been reduced by 1/3." The frequent change of staff highlighted one of the respondents, who stated that "there is a need for improvement, such as developing a cooperative spirit, adopting common goals, having a common vision, in our school. But because staffs are often changed, improvement is delayed." It is also worth mentioning the view of one of the participants, who described the culture as "random and proportionate to the individual culture that each one has from family and personal pursuits", while another teacher emphasized that in the school unit he serves "there are no traditions of any kind at school. The meaning of school culture derives from students' academic success". Negative was the view of yet another teacher, who stated that "There is no one common culture. There are teachers who try to produce. There are also teachers who have the mentality of a "typical public servant" and they are counterproductive." Another negative point of view is the following: 'Bureaucratic perception. The main goal of students is to enter the university. The only exception: some European programs that promote different educational goals. In general, however, there is a particularistic and utilitarian attitude towards knowledge."

In general, teachers reported that the culture in the school unit they serve is moderate to satisfactory, mainly due to teacher's good behaviour and to the relationships between teachers, and between teachers and students. The answer of one of the respondents is typical, and is considered representative of a large number of teachers involved in the research: "there is a culture of collaboration, which promotes the development of teachers with mutual support and agreement on educational values."

In addition, some teachers expressed the view that culture in their school is not outstanding. Characteristic is the response of one of the participants: "I think that culture is the driving force behind the school. It is a characteristic feature that gives a distinct entity. It is an important factor in shaping the character of school members. Unfortunately in our school the level is not very high, but there is something that gives us hope for future improvement."

However, there are many who argue that school culture is influenced by the way society thinks and acts, as the following answers demonstrate:

- $\quad$ "In a provincial school, school culture is directly influenced by the local social and economic factors. All members of the school community shape together the culture of the school, which must be open to partnerships with the local and wider community."

- $\quad$ "Culture is shaped by the students' rural-middle class family background as well as by the general political context of the societystate. School mitigates differences between foreign and local students." 
- $\quad$ "Culture in our school is influenced by the lifestyle and the way of thinking of the local community, the stereotypes that dominate the local provincial environment but also by the effects of online media. In general, values such as courtesy, mutual respect and solidarity survive, while the main objective of students is to perform well, which will ensure later their entry into higher education."

- $\quad$ "The importance of school culture derives from its relationship to students' academic success, but mainly to the functioning of the school community. More specifically, depending on whether members of the school community accept its goals and determined by the teachers' attitudes towards their work, it is believed that, through its culture, school can act either as a remedy to erroneous upbringing or vice versa as an amplifier to an upbringing that drives young individuals into social exclusion.»

- $\quad$ The culture that characterizes the school relates to the culture of the city we live in, i.e. a provincial town of 3,000 inhabitants, having all the features of a place faraway from large urban centres. Furthermore, it is certainly affected by internet influences (Facebook, twitter, etc.)."

- $\quad$ "The level, in my opinion, is low, since parents' only occupation is farming and fishing. There are, of course, excellent students, but few."

- "Culture levels are low, probably because the area is quite remote and the level of most students low as well. Many of the students are indifferent to school. They only think about their fields and animals. »

Another aspect of the school culture mentioned is the presence of foreign students, as well as the students' problems. According to one view: "School culture is almost non-existent due to many foreign students, students with financial problems, or separated parents. Students generally have many problems; their values and ideals have changed. Their basic needs are sometimes not covered at home." The following view was also expressed. "School culture is particular as many children come from troubled families. As a result, many children have different values and loose morals. "

Several teachers reported problems with student behaviour. As one teacher pointed out: "I could not say that I have seen something particular that would give me a negative impression of students' habits and values. There is something negative about the behaviour of some students, violence and disrespect among classmates and towards their teachers." According to another teacher's response: "Due to the fact that there are many foreign students, there are problems with behaviour and values", while another teacher stressed that "there is a rivalry between locals and foreigners that have failed to integrate." In the same context, a teacher stated that "foreign students have other habits and values, associate more with their compatriots and thus have no relationship with local children" because "each of them have other priorities and other values and ideals", While it was also mentioned that " there is no sympathy for foreign students ", something that results in problems and conflicts.

\section{More specifically, the following opinions were expressed}

- $\quad$ "Culture is made of basic assumptions, values and beliefs that are accepted and passed on to new members. But when the new members are people from other countries and another religions, then there is a problem. Culture could be eradicated. The result is a mixture that is often explosive (this has happened in my school)."

- $\quad$ "School culture levels are low because there are many students from different countries. Culture should act as a social bond in school and set patterns of behaviour. This is not the case in our school; on the contrary there are disputes between pupils. "

- $\quad$ "In our school there is a 'Balkanization', a culture that is made up of different subcultures of pupils competing for positions and excellence. So there are disadvantages to learning, teaching, discipline and curriculum."

- $\quad$ "Due to the fact that there are many students from other countries, school culture is degraded. And that affects the behaviour and performance of students as well as teachers. "

\section{DISCUSSION}

According to the survey results, the overwhelming majority of secondary schools in the North Aegean Region does not have a secretary at the school, and the principal already has several responsibilities, while the big problem is the centralized and bureaucratic nature of the administrative organization model of the educational system, but also of the administration and organization of the school units. The nature of this model makes it incomplete, time-consuming, perfunctory, irrational, inadequate and ineffective, which means that principals and teachers do not have the flexibility to take initiatives that will improve the quality of education and teaching at the school unit they serve according to the needs of students and the local community, and based on the school's connection to the wider society and the changes that are taking place in its environment. In addition, it was emphasized that this model, in addition to making school units more difficult to operate, also results in a misallocation of staff and consequently increased costs [14].

An interesting fact emerging from the present research relates to the school culture. Most of the teachers reported satisfactory to very high school culture, primarily as a result of the very good relationship, team spirit and atmosphere of support and cooperation between the teaching staff and secondarily as a result of the compliance of teachers, the principal and pupils with rules of conduct, values and standards. Indeed, the climate of unity, cooperation, support, creativity, innovation and communication between teachers but also between teachers and principals was mentioned by the majority of teachers as the strong point of the school unit in which they serve [15]. However, there were a number of teachers who emphasized the poor school culture or even the lack of it, which on the one hand derives from the low level of pupils, because of the way the local community acts and thinks, as well as the school's 
lack of connection with the local community, and on the other hand from the problematic coexistence of the local and foreign students, which often cause problems.

As regards the way the school unit operates, research has shown that it does not suffer from lack of cooperation among school unit members, ineffective leadership, inadequate guidance and encouragement from teachers, or from lack of effective communication. Specifically, on the question of communication, respondents' responses indicate that communication between school unit members is largely effective. However, their responses have also shown that communication between the school unit and parents as well as between the school unit and the local community is either moderately or to a small degree effective. These results illustrate the problematic connection of the school unit with the local community, as mentioned earlier, but also of the school's poor communication with the students' parents. These two parameters were also mentioned by some teachers as the cause of ineffective communication [16]

In particular, the indifference of parents and the local community, as well as the political controversy of the local community and the school bodies, appear to be two major causes that lead to ineffective communication within the school unit. Another reason cited by few teachers is the lack of vision on the part of school leadership [17].

Regarding the issue of leadership, reported as a factor contributing to the smooth functioning of the school unit, respondents' answers indicate that almost half of the teachers believe that the principal in the school unit they serve has the necessary skills and abilities to meet the requirements of this position.

In particular, to a large extent, the principal of the school unit in which the respondents are serving creates a positive climate, has the skills necessary to effectively resolve conflicts and to settle any problems that arise most effectively and appropriately, has a vision for the future and transmits it to teachers, sets priorities, reinforces school morale, cultivates awareness and critical consciousness, has the ability to forward the necessary changes, adapts the school to the new teaching methods required by the information and communication society, enhances and promotes teachers' job satisfaction, as well as their personal and professional development, the effective learning process, the communication with parents and students, teachers' participation in the decisionmaking process, social justice and the democratic spirit [18]

\section{The abilities and skills that a school principal should have are summarized as follows}

- The principal should be a leader (have a vision, be visionary, have high motivations and goals, provide motivation and support to teachers, deal with problems efficiently, effectively manage any conflicts and crises at school, create positive school climate).

- The principal should have communication and social skills (be communicative, have control and persuasion skills, be flexible with regard to the program and be versatile, have excellent computer skills and be innovative, should be characterized by ingenuity and determination).

- A principal should have organizational skills (to distribute competencies, to be methodical, to co-ordinate the learning process, to have passion and interest in guiding the school in pedagogical and scientific matters, to be aware of administrative and organizational issues, to be able to handle multiple requirements, work with other schools, come to school early and devote many hours to it).

- A principal should have emotional understanding and psychological status (to be sensitive, to love children, to be patient).

- A principal should be characterized by meritocracy, impartiality, boldness, justice, humanity, faith in truth [17].

Another operation feature of the school units involved in the survey is the lack of school evaluation. The lack of an assessment method is a result of the sparse visitation of school counsellors, because the school units are in a remote area, the assessment is not set as a priority by the teachers' association, the school unit or the ministry itself, and moreover it is not promoted by the teaching stuff, especially by trade unionists. Some of the few teachers mentioned that there is some method of evaluating the school units, pointing out that it is mostly done by the school principal, which does not render the evaluation process objective. Some of the teachers mentioned that self-assessment is done by pedagogical meetings, the school's annual operation report carried out by the principal, and by the indicators of the sustainable school. However, it should be noted that there are very few schools where such assessments are made [19].

Thus, almost half of the teachers involved in the survey consider that the climate in the school unit they serve is largely effective. In addition, less than half say they are happy with the quality of the educational process in the school unit they serve [20] However, others expressed a different view because of problems at the organizational and operational levels.

\section{CONCLUSION}

The effectiveness of a school unit cannot be easily determined. This is mainly due to the different model of organization and administration that each school unit has adopted. As regards the factors that contribute to school effectiveness, the above analysis has shown that there is an inseparable link between school unit leadership and school effectiveness. It should not be considered that leadership has only a direct impact on learning outcomes but also an indirect on the school unit through its influence on schoo 
organization and school culture [1]. An effective school principal-leader assists and supports teachers, while overseeing the educational work, and also encourages and promotes the involvement of teachers and parents in the decision-making process, which leads to the commitment of teachers to the school organization and increases their job satisfaction and performance [2]. According to the survey results, the overwhelming majority of secondary schools in the North Aegean Region does not have a secretary at the school, and the principal already has several responsibilities, while the big problem is the centralized and bureaucratic nature of the administrative organization model of the educational system, but also of the administration and organization of the school units. The nature of this model makes it incomplete, time-consuming, perfunctory, irrational, inadequate and ineffective, which means that principals and teachers do not have the flexibility to take initiatives that will improve the quality of education and teaching at the school unit they serve according to the needs of students and the local community, and based on the school's connection to the wider society and the changes that are taking place in its environment. Moreover, it was emphasized that this model, in addition to making school units more difficult to operate, also results in a misallocation of staff and consequently increased costs [7]

An interesting fact emerging from the present research relates to the school culture. Most of the teachers reported satisfactory to very high school culture, primarily as a result of the very good relationship, team spirit and atmosphere of support and cooperation between the teaching staff and secondarily as a result of the compliance of teachers, the principal and pupils with rules of conduct, values and standards.

As regards the way the school unit operates, research has shown that it does not suffer from lack of cooperation among school unit members, ineffective leadership, inadequate guidance and encouragement from teachers, or from lack of effective communication. Specifically, on the question of communication, respondents' answers indicate that communication between school unit members is largely effective. However, their responses have also shown that communication between the school unit and parents as well as between the school unit and the local community is either moderately or to a small degree effective.

Regarding the issue of leadership, reported as a factor contributing to the smooth functioning of the school unit, respondents' answers indicate that almost half of the teachers believe that the principal in the school unit they serve has the necessary skills and abilities to meet the requirements of this position.

Another feature of the operation of the school units involved in the survey is the lack of school evaluation. The lack of an assessment method is a result of the sparse visitation of school counsellors, because the school units are in a remote area, the assessment is not set as a priority by the teachers' association, the school unit or the ministry itself, and moreover it is not promoted by the teaching stuff, especially by trade unionists. Thus, almost half of the teachers involved in the survey consider that the climate in the school unit they serve is to a great extent effective $[16,21]$.

\section{REFERENCES}

1. Krüger, M. (2009). The Big Five of school leadership competences in the Netherlands. School Leadership \& Management: Formerly School Organisation, 29(2), 109-127.

2. Hulpia, H., Devos, G., Rosseel, Y. (2009). The relationship between the perception of distributed leadership in secondary schools and teachers' and teacher leaders' job satisfaction and organizational commitment. School Effectiveness and School Improvement: An International Journal of Research, Policy and Practice, 20(3), 291-317.

3. Heng, M. A., \& Marsh, C. J. (2009). Understanding Middle Leaders: A Closer Look at Middle Leadership in Primary Schools in Singapore. Educational Studies, 35, 525-536.

4. Rhodes, C., Brundrett, M. (2009). Leadership development and school improvement. Educational Review, 61(4), $361-374$.

5. Kotton, K. (2003). Principals and student achievement. What the research says. USA: Association for Supervision and Curriculum Development.

6. Cunningham, G., \& Cordeiro, P. A. (2006). Educational leadership: A problem-based approach third edition. Boston, MA: Allyn \& Bacon.

7. Zarotis, G., Ntalossis, D., Koukoli, M. (2019). Administrative organization of the greek educational system and forms of evaluation003). The essence of research methodology. Heidelberg: Springer - Verlag.

8. Scanlon, M. (2001). In International Journal of Recent Scientific Research, 10(E) 10: 35480-35485.

9. Jonker, J., Pennink, B. (2 Issues in research. In: Wilkinson, D (Ed.). The researcher's toolkit. London: Taylor \& Francis.

10. Creswell, J.W. (2002). Research Design: Qualitative, Quantitative, and mixed methods approach. London: Sage.

11. Wilson, N., McLean S. (1994). Questionnaire design: a practical introduction. University of Ulster Press: Newtown Abbery.

12. Dornyei, W. (2003). Questionnaires in second language research. New Jersey: Lawrence Erlbaum Associates, Inc.

13. U.S. Office of Personnel Management. (2008). Structured Interviews: A practical guide. Available on the website: https://apps.opm.gov/ADT/ContentFiles/SIGuide09.08.08.pdf.

14. Ntalossis, D., Zarotis, G., Koukoli, M. (2019). Education and effective school. International Journal of Information Research and Review, 06(8), 6408-6416.

15. Tsayang, G., Monyatsi, P., Bulawa, P., Mhozya, C. (2010). An Evaluation of the Sustenance of the Primary School Management Development Project in Botswana. Journal of Social Science, 23(2), 111 - 121. 
16. Ntalossis, D., Zarotis, G., Koukoli M. (2019). Organizational, operational and leadership theories of the school unit in greece. Journal of Humanities and Social Science, 24(9)2, 22-32.

17. Dean, J. (1993). Managing the secondary school. London: Routledge.

18. Krüger, M. (2009). The Big Five of school leadership competences in the Netherlands. School Leadership \& Management: Formerly School Organisation, 29(2), 109-127.

19. Eurydice. (2004). Evaluation of schools providing compulsory education in Europe. Brussels: Eurydice European Unit in: http://www.eurydice.org.

20. Hadzigeorgiou, Y,. \& Schulz, R. (2017). What really makes secondary school students "want" to study physics? Education Sciences, $17,84$.

21. Cohen, L., Manion, L., \& Morrison, K. (2007). Research methods in education (6th Edition). London: Routledge. 